\title{
4D Applications of GIS in Construction Management
}

\author{
A. Chaitanya Kumar ${ }^{1}$ and T. Reshma ${ }^{2}$ \\ ${ }^{1}$ KL University, Vaddeswaram, Guntur, Andhra Pradesh, India \\ ${ }^{2}$ Department of Civil Engineering, KL University, Vaddeswaram, Guntur, Andhra Pradesh, India \\ Correspondence should be addressed to T. Reshma; talarireshma@kluniversity.in
}

Received 14 February 2017; Revised 21 March 2017; Accepted 29 March 2017; Published 22 May 2017

Academic Editor: Deodato Tapete

Copyright (C) 2017 A. Chaitanya Kumar and T. Reshma. This is an open access article distributed under the Creative Commons Attribution License, which permits unrestricted use, distribution, and reproduction in any medium, provided the original work is properly cited.

\begin{abstract}
Construction industries broadly involve different set of construction activities which are to be executed as per schedule and the major software used for scheduling is PRIMAVERA and Microsoft Project (MSP). But the software still lacks a feature of providing spatial aspects of information in construction schedule. Recently, advanced technology like 4D GIS plays a major role in overcoming the limitation of the software. 4D GIS technology includes integration of 2D drawings from AutoCAD and schedules prepared in PRIMAVERA software. In the present study, a multistair residential building has been selected. ARCMAP 10.2 is used for interlinking of schedules as well as drawings and ARCSCENE has been used for developing 4D view. This linkage between scheduled activities and respective drawings in GIS helps in identifying construction sequences and also in detecting logical errors that occur in project schedules. The developed $4 \mathrm{D}$ view provides better visualization of construction progress of a project.
\end{abstract}

\section{Introduction}

Successful completion of a project is possible only by the proper planning and scheduling of activities. This Successful completion of project results in overall optimization in cost and time [1]. Construction progress of the project should be monitored at every time. Project monitoring acts as safety step in construction projects which alerts and advices the organizations about occurrence of construction failures and delays. It includes the process of collecting, analysing, and recording information regarding the project. Reference [2] describes some of the conventional methods which are widely used by the construction managers for scheduling are bar charts, critical path method (CPM), and program evaluation and review technique (PERT). Construction scheduling tools such as Microsoft Project (MSP) and PRIMAVERA are used for the preparation of construction schedule. These scheduling tools cannot be able to provide digital information (drawings) for the respective construction components and construction activities which are identified in scheduling software. For better understanding of construction sequence and for providing better visualization of the construction progress planner makes use of $2 \mathrm{D}$ drawings and integrates it with their corresponding component schedules in GIS software [3]. New advancements in GIS software are use of time component which helps planners in depicting real world components. Reference [4] explored the uses of GIS for CPM scheduling. Using 3D models and CPM schedules as inputs, linkage between the two has been made possible in GIS to develop a 4D model. Reference [5] suggested that GIS acts as a platform in which both spatial and nonspatial data, that is, drawing components and their activity schedules, are integrated for successful execution of the project by providing good visualization. Advanced visualization techniques such as $4 \mathrm{D}$ (3D geospatial + time component) and virtual reality should be utilized for more effective evaluation and communication of construction project schedule information. Therefore, it becomes easy to find errors in schedule, and small activities can also be completed without any delay. This $4 \mathrm{D}$ GIS view provides better visualization progress of a construction project and makes the planning sequence and execution easier to understand and allows a planner to visualize the construction process in the way it would actually be built [3]. Comprehensibility in the project schedule will 
decrease the potential errors and conflicts in the schedules during the construction. Building plan with the corresponding themes related to elevation as a shape file using GIS software was connected with the schedule for construction activities developed using PRIMAVERA project planner and synchronized the same with time.

1.1. Role of GIS in Construction Management. Nowadays Geographical data system applications are mostly used in construction industries. The limitations of a schedule generated in PRIMAVERA and Microsoft Project forced researchers to combine it with CAD drawings which leads to $4 \mathrm{D}$ GIS model. However in 4D model technologies number of researches are increasing rapidly. Reference [6] demonstrates that these models are not easier to use in construction industry and the visualization provided by them is not easily customized. Reference [7]. demonstrates that $4 \mathrm{D}$ models in construction industry hinder the collaboration between the contractors and subcontractors. Koo and Fischer [3] state that the construction industry needs a software tool which can easily generate, manipulate, validate, and interlinks the schedules with respective 3 -dimensional respective drawings in a single screen. The main role of GIS is to develop a strong GIS platform for seamless integration of databases generated across the projects with satellite imagery. Reference [8] demonstrates that linking between GIS and CAD with database management system has the potential to solve construction problems with the help of 3D models and CPM schedules. Basic concepts regarding this particular work are referred by following the above literatures stated and based on the cited literatures work is carried out by making some new advancements in the procedures of the work which is stated in the above literatures. This work using GIS provides $4 \mathrm{D}$ visualization progress of project along with scheduled quantities stored in database management. The major aim of this study is to make use of GIS for scheduling activities and interlinking it with $3 \mathrm{D}$ drawings provides better visualization of construction progress.

1.2. 4D GIS Modelling. A four-dimensional geographic system (4D-GIS) is employed as both spatial and nonspatial data processing platform. 4D-GIS effectively integrates, manages, and analyses spatial information and nonspatial information, outlined as $4 \mathrm{D}$ information $(2 \mathrm{D}, 3 \mathrm{D}$, and time amendment data). 4D modelling tool is a dominant tool that provides good visualization, simulation, and communication which gives concurrent access to style and to schedule information. It provides graphical presentation of work order which enables immediate identification of issues together with interface exposure and supports situation analysis. This $4 \mathrm{D}$ tool helps knowledge in collaborative construction techniques, analyses and provides a mean for graphically representing the overall construction process, and facilitates all participants in project for better decision making process [9]. This $4 \mathrm{D}$ planning tool also helps the planners in reducing the schedule conflicts, analysing of constraints, and evaluating different construction ways [10]. Visualizing construction progress in 3-dimensional view along with CPM generated schedule helps the construction manager in a project with an automatic view of project sequence. $4 \mathrm{D}$ visualization helps the project planners in viewing the progress of construction activities in a project at any level. The benefits of linear scheduling and $4 \mathrm{D}$ visualization include the ease with which different scheduling techniques are used and the linkage between activities and schedule information provides up to date information and also reduces incompleteness in information [11]. Reference [3] said that 4-dimensional model will increase understandability of the schedule of project and makes the user observe serious risks during execution of the project. Spatial and nonspatial information related to the project is integrated in GIS platform and they are analysed, managed, and finally displayed. The spatial data means drawings which are directly related to geometry of features of a layer in GIS. Spatial features are represented in GIS with the help of vector data and raster data models. The occurred 4D GIS view provides better visualization progress of a construction project and makes the planning sequence and execution easier to understand. This 4D GIS model reduces cost overruns of the projects by early identification of problems, such as timespace conflicts, safety concerns, and working place restrictions.

\section{Methodology and Model Development}

Methodology has been developed for integration of GIS and PRIMAVERA for preparation of $4 \mathrm{D}$ construction schedule. Figure 1 shows various steps involved in model development.

Collection of 2D Drawings. All structural drawings and 2D plans of the building which is being constructed have to be collected. For getting better output, it is mandatory to have the plans at different stages of construction project. These drawings can be generated in digital environment like AutoCAD.

Create Work Breakdown Structure. Based on the type of construction project, various construction activities have to be defined. A Work Breakdown Structure (WBS) has to be prepared with the defined activities. Preparation of WBS involves a unique approach for various outcomes.

Importing of Drawings to GIS Environment. The digital drawing files are exported to GIS software environment. The topological structure of the layers can be created in GIS software as identified in the drawings.

Georeferencing and Digitizing in GIS Software. Imported drawings are georeferenced with respective coordinates on all sides and digitized into required shapes by creating shapefiles.

Schedule Preparation for Activities in Work Breakdown Structure. The project will be scheduled depending on activities which are listed in the Work Breakdown Structure. Project management software PRIMAVERA has been used for preparation of schedule which shows start dates and end dates, along with critical path(s) and the activity sequences and interrelation between activities can also be shown. Task 


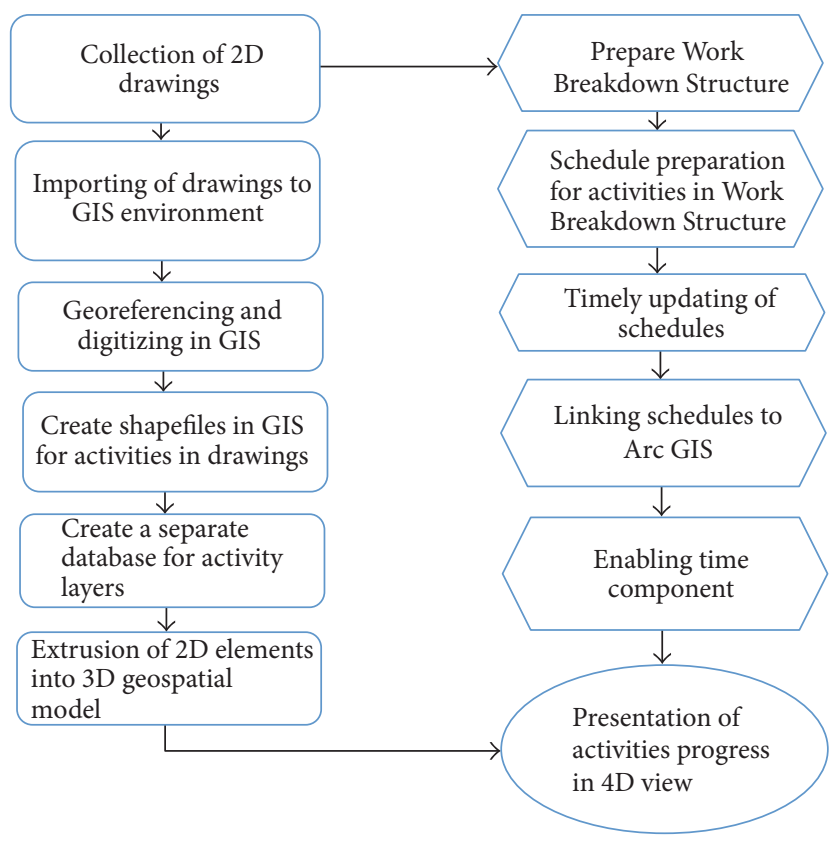

FIGURE 1: Flowchart for the model development of 4D GIS.

names for the activities are given same in project management software and GIS for the purpose of interlinking.

Timely Updating of Schedules. The schedules like start date, end date, and so forth created in planning software have to be updated periodically.

Creation Database for Activity Layers. Shapefiles which are created by the process of digitization should have separate database which stores data about each activity in it.

Linking of Schedules. Schedules which are updated after creation in planning software have to be linked with GIS software. Activity names and IDs for activities in which drawings and schedules are to be interlinked should be same.

Creation of 3D Geospatial Model. The 3D view of the project is created in ARCSCENEwhich is another module of GIS software. The activity layers which are created earlier are converted into 3D layers in ARCSCENE. The 3D file developed should have the same resource data as like in schedule.

Preparation of Final 4D Output. The concluding step in this process is integration of $3 \mathrm{D}$ drawings with their respective schedules prepared from planning software PRIMAVERA. Both drawings and schedules should contain same feature classes and same names for activity layers for the purpose of integration. Final result can be viewed in rendered $3 \mathrm{~d}$ simulation along with the displayed time line slider. The developed GIS based application in planning and scheduling can be used for repeated tasks of works. In this step the drawings are provided in $3 \mathrm{D}$ view along with the respective schedules of each activity which provides better visualization of the construction project and provides the better understanding of the activity sequence in the project. The final output is termed as $4 \mathrm{D}$ drawing, that is, $3 \mathrm{D}$ view along with time component.

\section{Study Area and Application}

The proposed methodology of integration of PRIMAVERA and ArcGIS mainly for scheduling and monitoring the construction progress of project is applied on a residential multistair building. The 2D drawing of the building at different levels of the construction work and different activities from WBS are imported into ArcGIS software.

Collection of 2D Digital Drawings. The 2D plans of the building that was drafted in AutoCAD for particular project were collected in required format. Work Breakdown Structure (WBS) for the building activities has been carried out. Construction activities constitute structural work, plastering, brickwork, and finishes. More accurate 2D plans give more accurate $3 \mathrm{D}$ model of the building.

Schedule Preparation in PRIMAVERA Software. Proper scheduling and planning of construction projects are necessary for construction outcomes for reduced and less dominant delays of the project. Proper scheduling of activities is required to track the project during its execution. A warning mechanism which might alert the construction industry regarding its attainable success as well as failures throughout the project has to be present. The main aim of this study unit is to set up, schedule, monitor, and track the residential project with facilitation of PRIMAVERA software and understanding of results generated and its potential to counsel that methodology is appropriate for chosen residential building. 


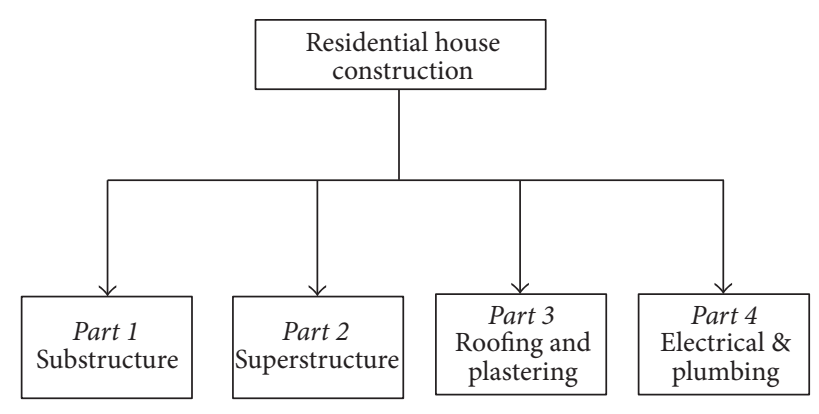

FIgURE 2: Work Breakdown Structure for a residential building.

In construction projects, (CPM) networks, PERT networks, and bar chart techniques and are most commonly used for schedule preparation. It includes the calculation of the first and also late beginning of activities, slack times, and float of the activities and also timely allocation of resources for the activities which are in schedule. Due to some of the deficiencies in bar chart method CPM method comes into existence to prepare the schedule and track the project. CPM method provides minimum amount of time needed for completing of activities and provides a complicated warning regarding issues that may occur. Variables such as activity durations, earliest start times, late start times, early late completion times of activities, and total budget of the project have direct effect on completion of construction project. Thus CPM assumes previous expertise with similar project works from that the relationships between resources and job times are made available. Different type's activities in a project prepared by CPM network are associated with more additional elements of a project. Schedule preparation for projects involves two steps.

3.1. Identification of Work Breakdown Structure (WBS) for Different Activities. Scheduling actually cannot be accomplished until a Work Breakdown Structure is laid out. A WBS is a main deliverable of a project that formulates the team work into different work sections. Project Management Body of Knowledge (PMBOK) says that the WBS is a "hierarchical decomposition of the work which is deliverable oriented to be Performed by the project members." WBS acts as both the model and work measuring baseline tool for project management. WBS clearly defines the scope of the work into different sections so that the members of the project team will understand every level of details in the project. Figure 2 shows a sample WBS with four levels defined. WBS starts with the top level projects deliverable at first and is further divided into subsections by using outline hierarchy chart. WBS is one of the foremost vital outputs of the planning process because it unambiguously guides the scheduling of the project by shaping and grouping of work tasks.

\subsection{Preparation and Initiation of Schedule for Identified} Activities. Scheduling is the process of allocation of resources for the activities identified in WBS which are required to complete the project in a stipulated time. The initial proposal of the study involves scheduling being done in the project management tool PRIMAVERA. This tool enables the effective scheduling related to work to be handled and it results in providing critical path for the project.

Steps involved in developing schedule are

(1) estimation of time required for completion of each activity in a project;

(2) setting out time intervals to each activity for start and finish;

(3) adding logical relationship to activities.

WBS is created to make the project efficient and manageable. Construction activities which are to be added in the PRIMAVERA for the scheduling of the building are Base floor, Base steps, Columns, Beam (1), Beam (2), Back face wall (1), Back face wall (2), Exterior left wall (A) (B), Exterior right wall (A) (B), Interior left wall (A) (B), Interior right wall (A) (B), Middle wall, Slab, Windows, Lintels, Windows, and Doors. Figure 3 shows generated schedule based on the calculated data, time, and requirements of labour.

Modelling of $2 D$ View to $3 D$ in ARCSCENE. The main objective of this step is to extrude the activity layers which has been created earlier in ARCMAP into 3D. This decisive step is in ARCSCENE software. ARCSCENE is a $3 \mathrm{D}$ visualization tool which facilitates in elevating spatial data into three dimensional. Steps involved in extrusion of 2D elements to 3D in ARCSCENE are as follows:

(i) After digitizing the drawing to the required shape, it is then replicated to topology which converts feature classes to polygons.

(ii) After creation of topology the shapefile is imported to ARCSCENE environment for the purpose of extruding each feature class into 3 dimensions.

(iii) For projecting the image into $3 \mathrm{D}$ the coordinate system must be projected properly from geographic coordinate system to projected coordinate system, that is, WGS 1984 UTM ZONE 44N. These coordinate systems are for the particular region where study area is located.

(iv) Building shapefile in ARCSCENE is extruded into 3D model by giving elevation value to each activity layer. All the features of a building are extruded based on 


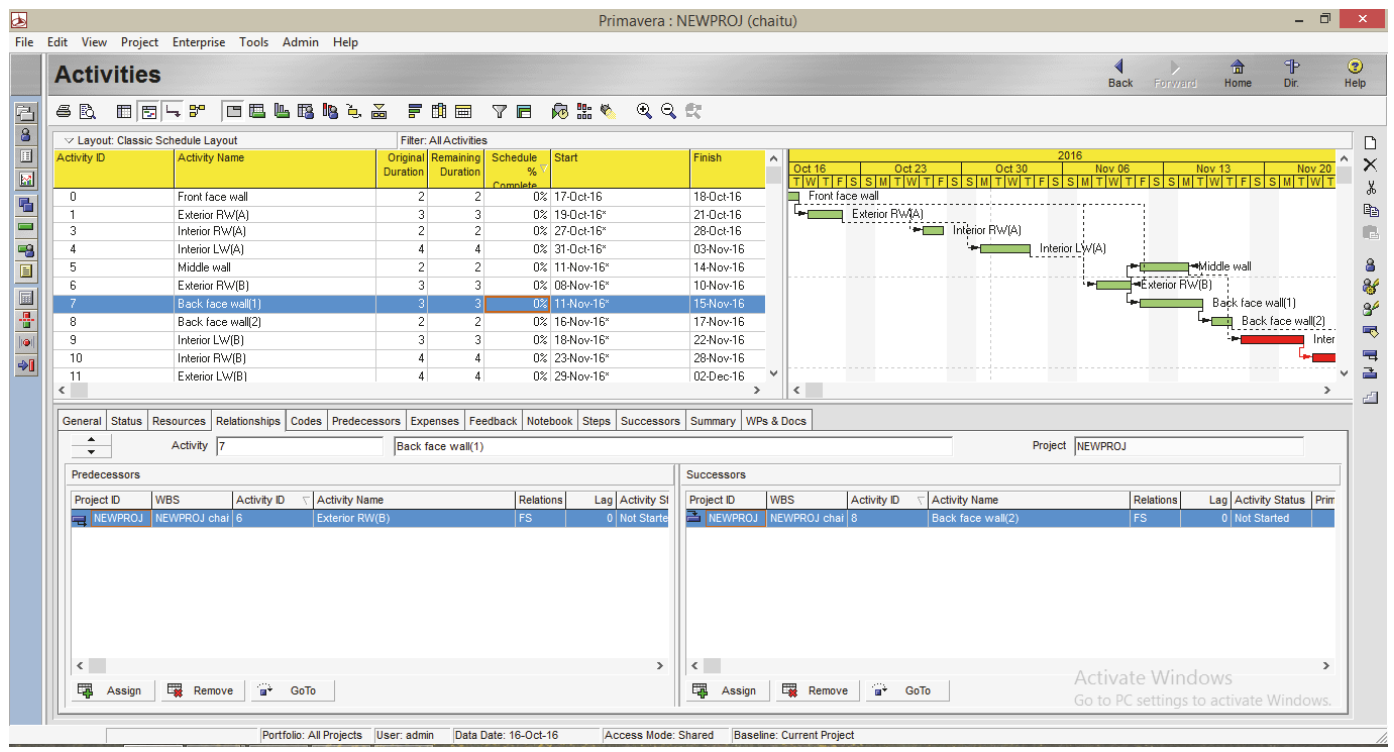

FIgURE 3: PRIMAVERA generated Schedule.

their standard elevation value from base level to floor level depending on its service.

(v) Figure 4(a) shows 2D plan of the building opened in ARCSCENE in Isometric view.

(vi) Figure 4(b) shows the elevated structural part of the building with $3 \mathrm{~m}$ of height.

(vii) Figure 4(c) presents room sections which are divided by partition walls.

(viii) Figure 4(d) shows elevation of remaining structural elements of the building like lintels, windows, door frames, and so forth.

(ix) Figure 4(e) shows the complete elevation of components of first floor of the building

(x) Figures 4(a)-4(e) shows the layer-wise 3D extrusion of building project.

(xi) Figure 4(f) shows the complete 3D elevated view of the building along with their structural components.

Importing of Schedule to ArcGIS Software. Detailed schedule prepared for the activities of the building has to be imported to ArcGIS software for the purpose of interlinking it with the $3 \mathrm{D}$ simulation output. The prepared schedule was saved in Excel format and it is exported with the help of exporting option in PRIMAVERA. The detailed schedule which is prepared in PRIMAVERA software is exported and stored in GIS database. The attribute data in the Excel file may get lost if it is imported to the GIS software in Excel workbook format. CSV (comma-delimited) format is able to transfer data from one application to another application without losing any data. This imported schedule can be updated at any stage of the project.

Staging of 4D View by Integration of Schedule and Drawings. This is the crucial step in overall simulation of the project.
This step involves the integration of 3D drawings which are created and extruded in GIS and schedule prepared in PRIMAVERA to provide better visualization of construction progress of the project. This dynamic linkage helps in detecting deficiencies and logical errors in scheduled project. Every activity in the project is provided with time component. Interlinking between scheduled data and drawings will be done only if the activity layer names and IDs for activities are the same. It will keep only the matching records in both digital data and scheduled data. Unmatched records will be left as null values for all the remaining fields in the attribute table. After interlinking of both spatial and nonspatial data of the building $4 \mathrm{D}$ view of the building is presented in a single screen environment. Figure 5 shows the complete 4D view of building along with their respective schedule for each component.

Time line slider is also assigned to the $4 \mathrm{D}$ drawing which shows the timely extrusion of each component with respect to their derived schedules. 3D components are elevated periodically with their respective schedules by time line slider which are linked to them earlier. Figure 6 shows the simulation of the construction planning process along with time line slider for first floor of the building. Figure 7 shows the timely extrusion of structural components of second floor of the building along with the prepared schedule on a single screen. Finally Figure 8 shows the overall details of a project from beginning to end along with the schedule information being seen in a single environment in $4 \mathrm{D}$ view which provides good visualization of construction project.

\section{Discussion and Conclusions}

The proposed methodology in this paper strongly promotes $4 \mathrm{D}$ GIS concept to integrate and represent spatial and nonspatial information like project drawings, resources, specification, and the schedule prepared in a single environment. 


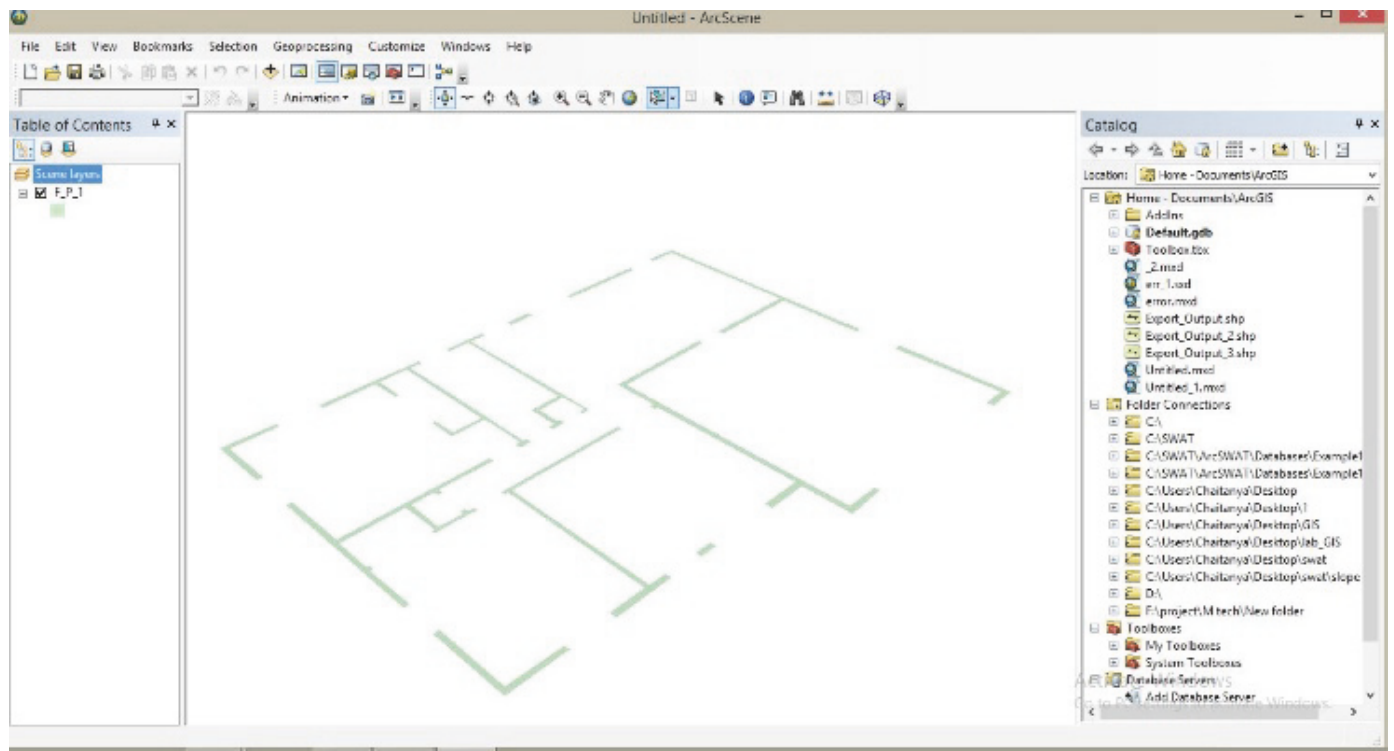

(a) Isometric view of plan

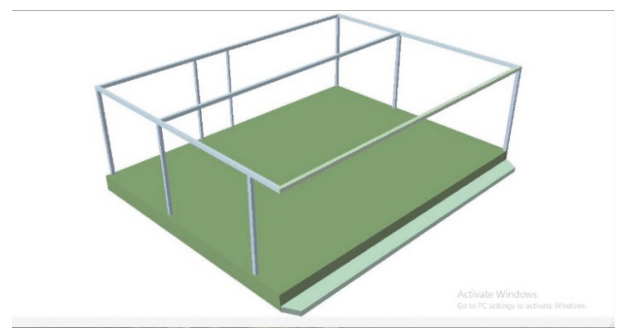

(b) Complete structural view

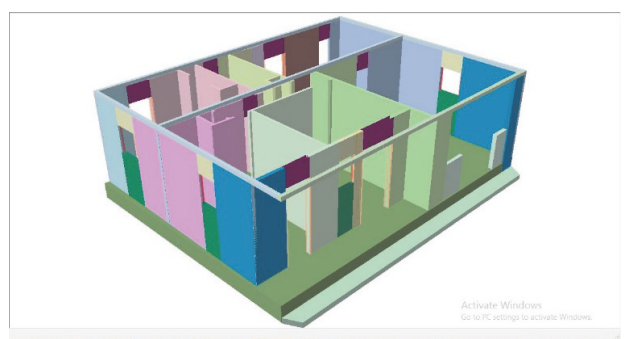

(d) Complete 3D view of interior part of building

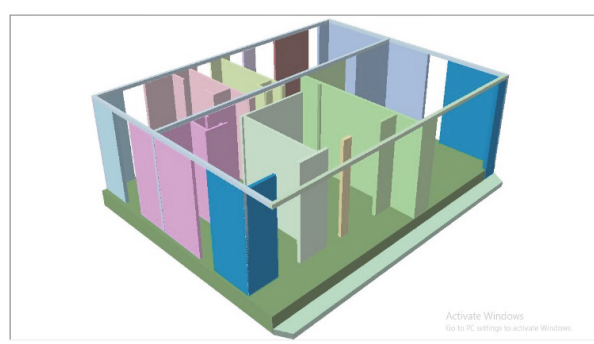

(c) View of internal partition walls

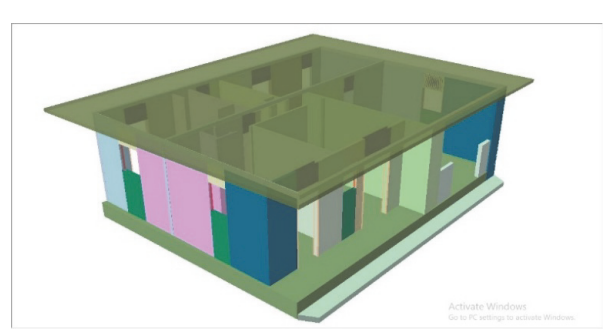

(e) Elevated 3D view of the first floor of the building

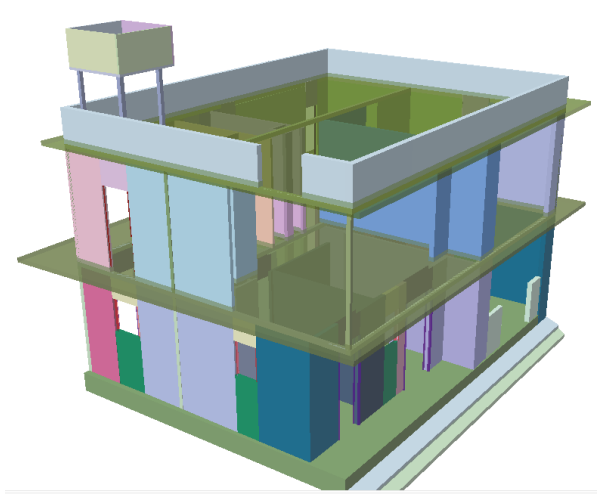

(f) Complete 3D view of the building

Figure 4 


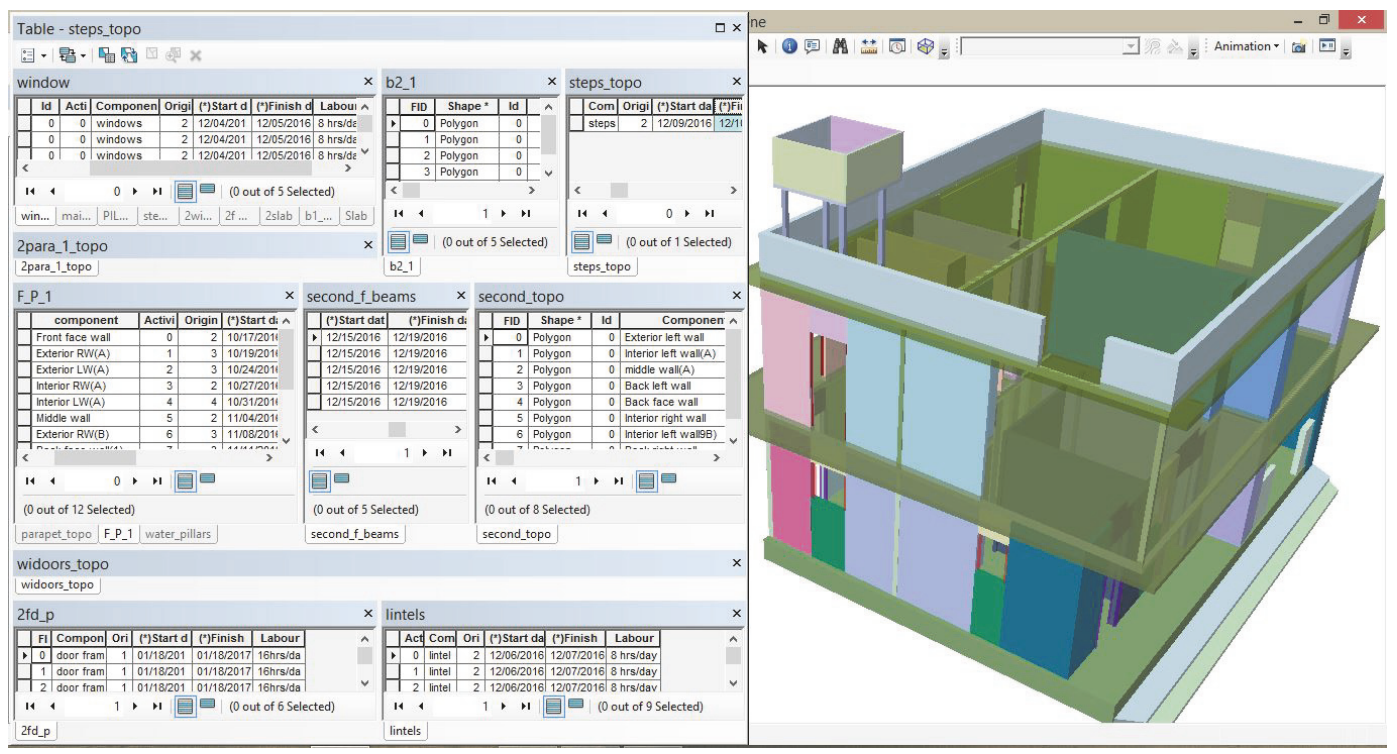

Figure 5: Complete 4-dimensional view of building.

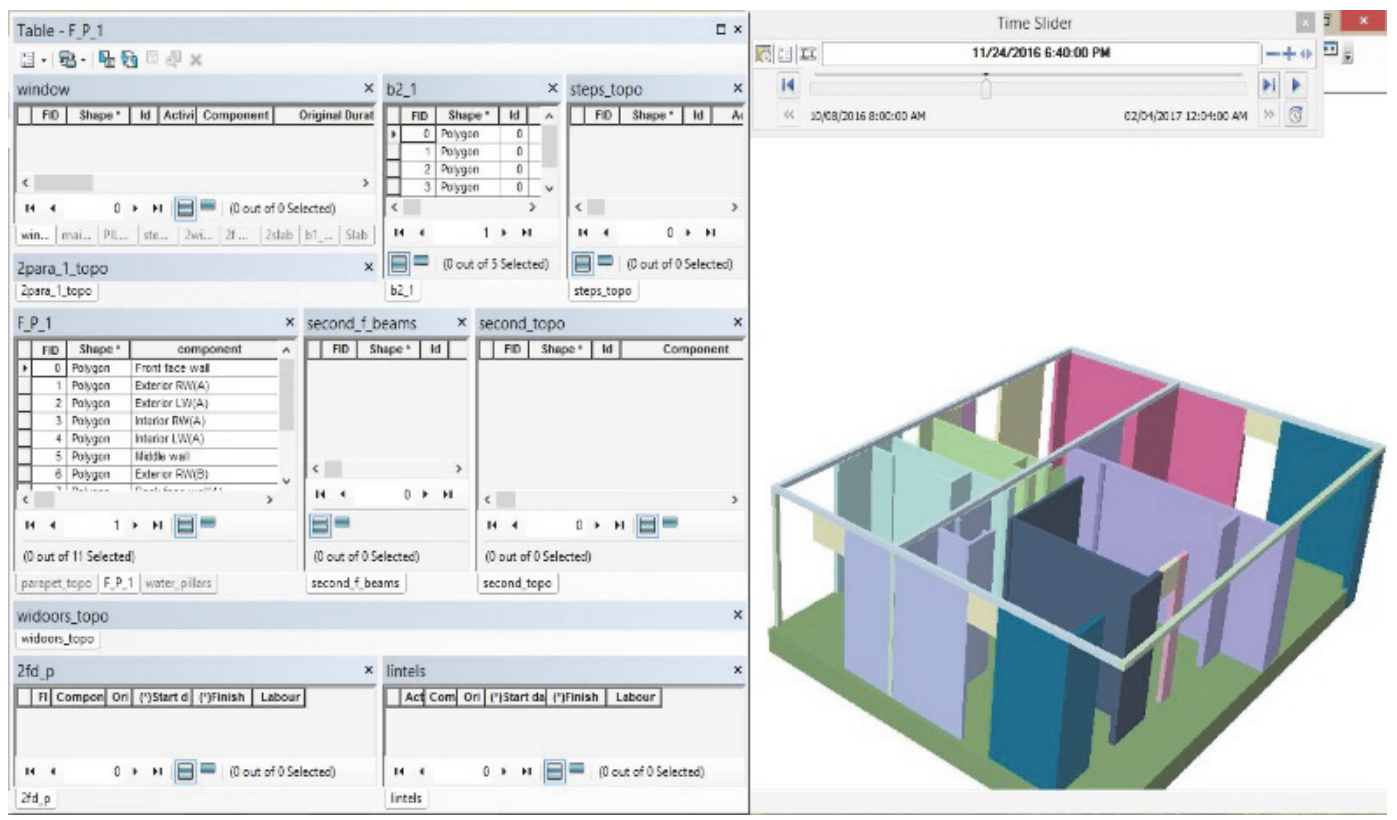

FIgURE 6: Extrusion of first floor components.

Integration of PRIMAVERA and GIS has been done to develop a $4 \mathrm{D}$ model which provides the better visualization of the construction progress of the projects. This linkage between scheduled activities and respective drawings in GIS helps in identifying construction sequences and also in detecting logical errors that occur in project schedules. 4D GIS tool has various advantages which have been increasingly used to not only incorporate spatial relationships but also analyse and visualize space across time. 4D GIS has become particularly essential in areas where GIS is needed for predicting dimensions across time. Apart from 4D GIS method the remaining methods which are followed in construction industry are not capable of providing spatial relationship between construction activities and cannot control cost overruns of the projects by early identification of problems, like timespace conflicts, safety concerns, and working place restrictions, and so forth. All these can be overcome by 4D GIS. So these aspects have made 4D GIS increasingly needed as a real-time platform that also offers not just current monitoring of events but can take input or data gathered and predict what could happen as a type of forecasting tool. The integration of GIS \& PRIMAVERA helps all the workers in 


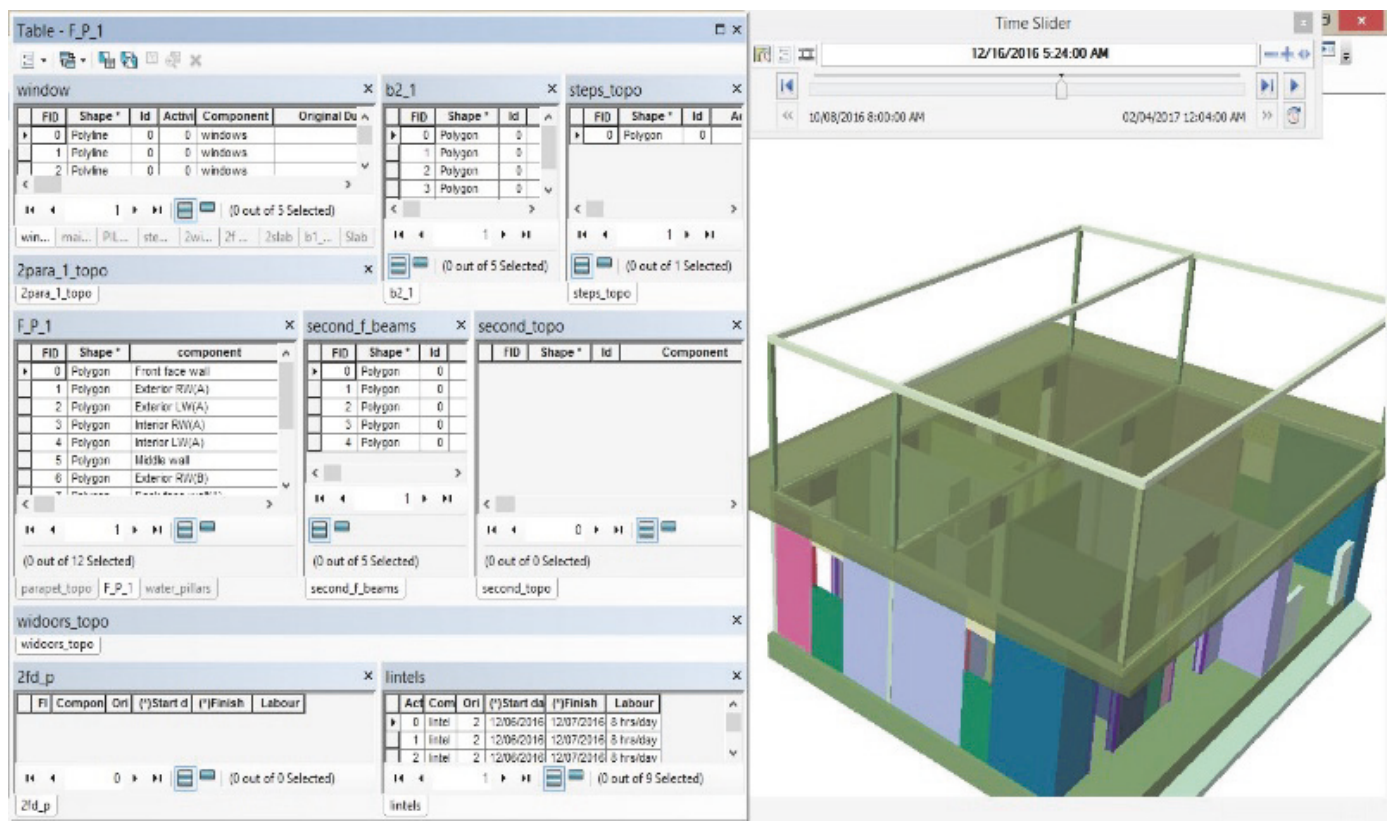

FigURE 7: Extrusion of second floor components.

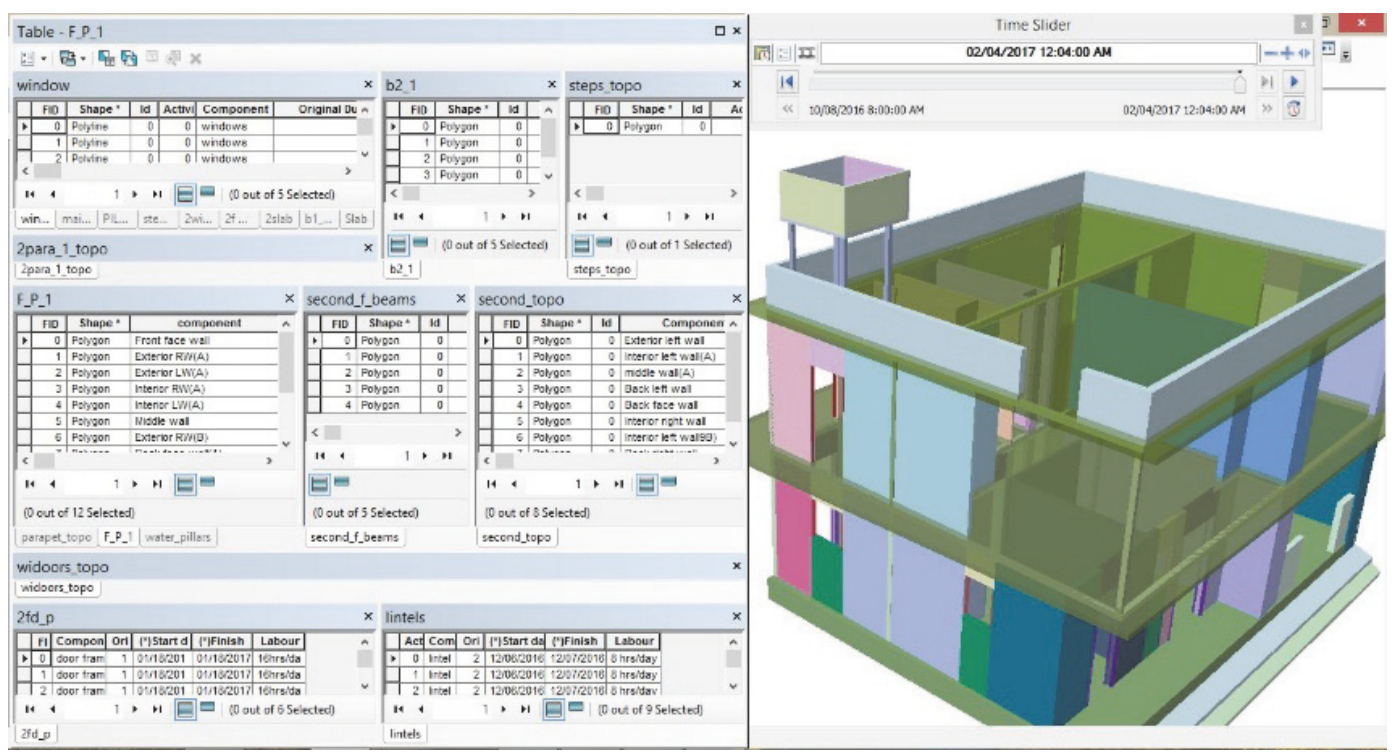

FIgURE 8: Final complete 4D view along with time line slider.

the construction project majorly for making of decisions as they can see all those spatial drawings and nonspatial details of a construction project in one environment. 4D GIS tool provides infrastructure monitoring which needs to analyse where and when vulnerabilities may arise in infrastructure due to depletion or events. However the methodology presented in this paper is useful for efficient scheduling of major construction activities of any infrastructure project. This 4D tool helps knowledge in collaborative construction techniques, analyses and provides a mean for graphically representing the overall construction process, and facilitates all participants in project for better decision making process. This methodology not only provides good visualization of construction activities but also provides timely extrusion of each component along with the schedules. Major amount of rework in a project is avoided by the early notification of problems from layer-wise $4 \mathrm{D}$ views of the construction project. This method requires careful planning of activities and their linking along with drawings. This study considers only important 3D visual structural activities except electrical, flooring, internal finishes and carpentry work, and so forth. 


\section{Conflicts of Interest}

The authors declare that they have no conflicts of interest.

\section{References}

[1] U. Y. Polekar and R. R. Salgude, "Planning, scheduling and tracking of a residential project using Primavera software," vol. Volume 3, Issue 5, 2015.

[2] T. Subramani and M. Sekar, "Preplanning and scheduling of road construction by using PPM," International Journal of Application or Innovation in Engineering \& Management, vol. 4, no. 5, pp. 234-244, 2015.

[3] B. Koo and M. Fischer, "Feasibility study of 4D CAD in commercial construction," Journal of Construction Engineering and Management, vol. 126, no. 4, pp. 251-260, 2000.

[4] V. K. Bansal and M. Pal, "Generating, evaluating, and visualizing construction schedule with geographic information systems," Journal of Computing in Civil Engineering, vol. 22, no. 4, pp. 233-242, 2008.

[5] V. R. Keesara and D. Karthik, “4D planning and scheduling of the construction project using project management software and GIS," Geoinformatics \& Geostatistics, vol. 2, no. 3, 2014.

[6] R. R. A. Issa, I. Flood, and W. J. O'Brien, $4 D C A D$ and Visualization Inconstruction: Developments and Applications, A. A. Balkema Publishers, 2003.

[7] S. E. Poku and D. Arditi, "Construction scheduling and progress control using geographical information systems," Journal of Computing in Civil Engineering, vol. 20, no. 5, pp. 351-360, 2006.

[8] M. Y. Cheng and S. C. Yang, "Planning, scheduling and tracking of a residential project using Primavera software," Journal of Construction Engineering and Management, vol. 127, no. 4, pp. 291-299, 2001.

[9] K. Williams, B. Elizabeth, and M. Jenks, "Achieving the compact city through intensification: an acceptable option," in In The compact city: A sustainable urban form? pp. 83-96, 1996.

[10] B. M. Vagun, GIS applications for hazard preparedness, response, and mitigation, Graduate project, MSc in Interdisciplinary Science Studies [M.S. thesis], Johns Hopkins University, Baltimore, Maryland, 1996.

[11] S. Staub-French, A. Russell, and N. Tran, "Linear scheduling and 4 D visualization," Journal of Computing in Civil Engineering, vol. 22, no. 3, pp. 192-205, 2008. 


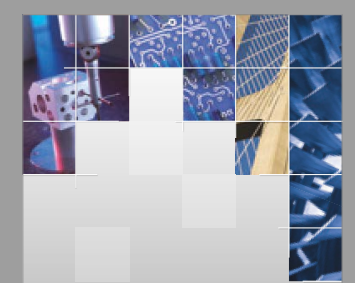

\section{Enfincering}
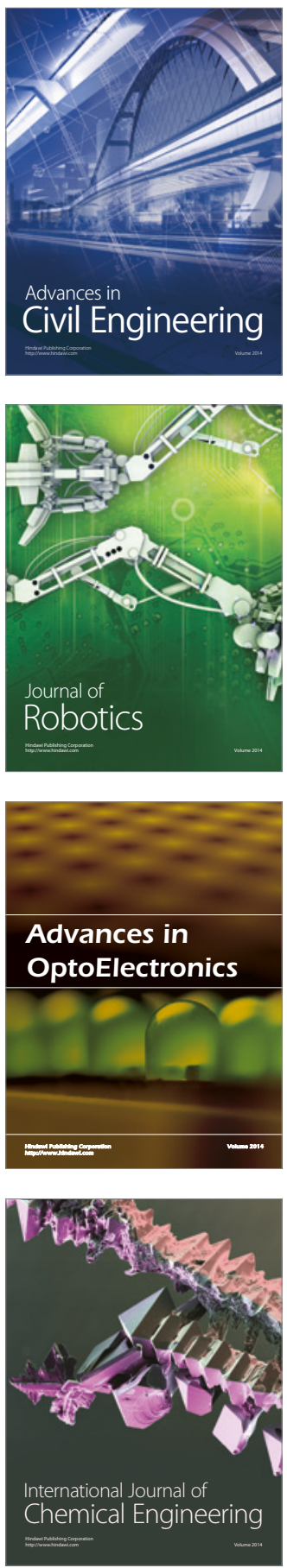

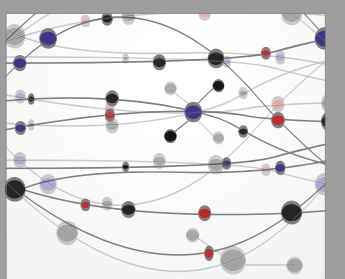

The Scientific World Journal

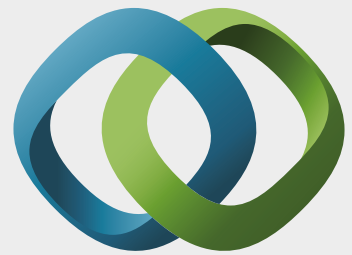

\section{Hindawi}

Submit your manuscripts at

https://www.hindawi.com
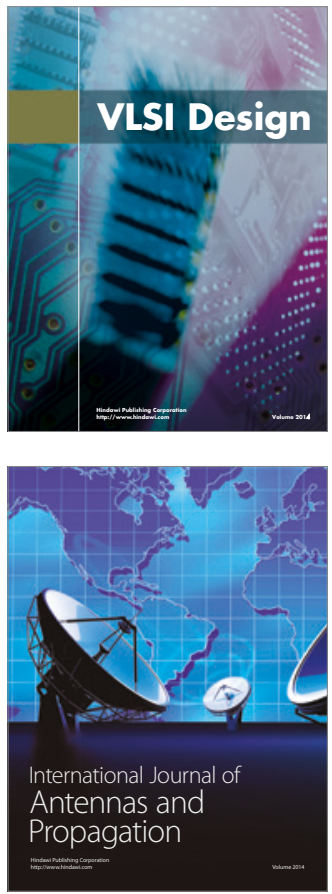

\section{Rotating}

Machinery
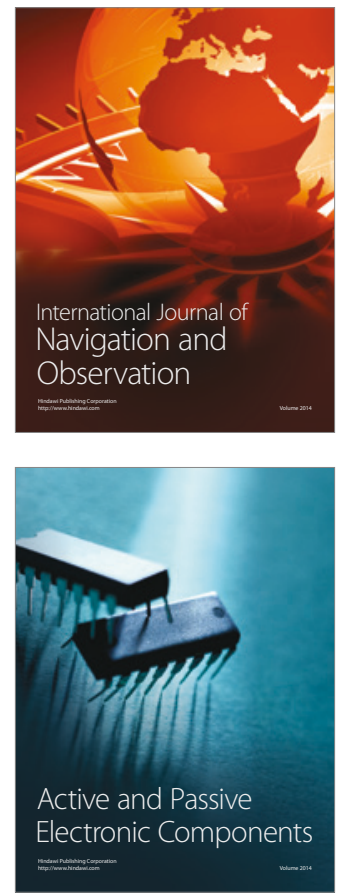
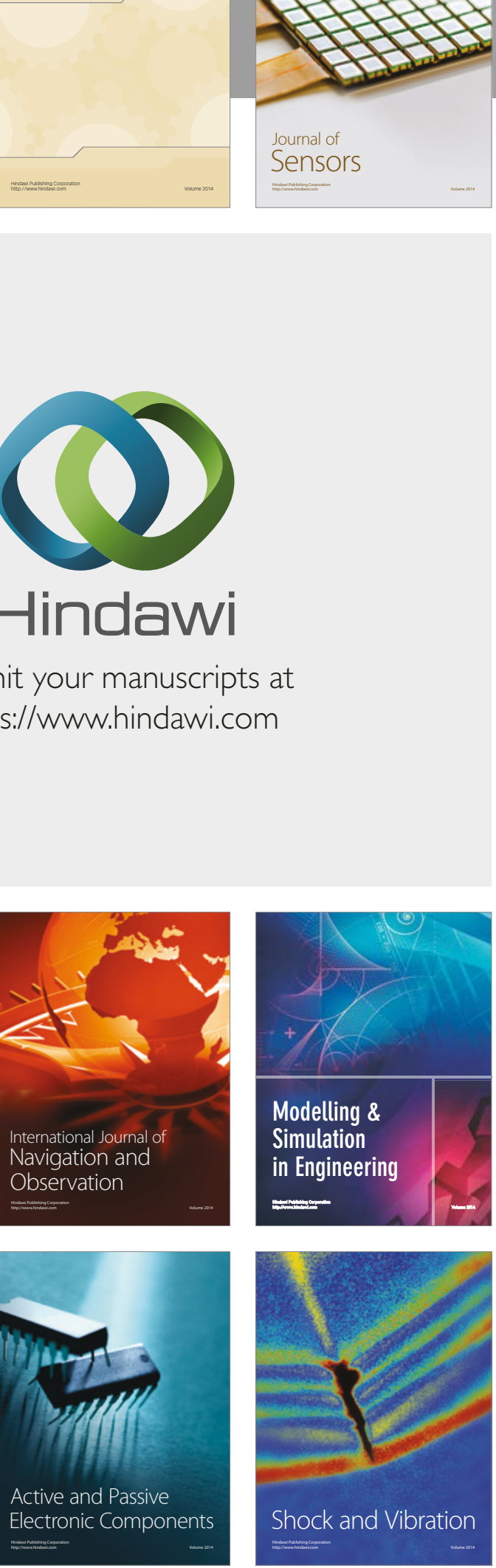
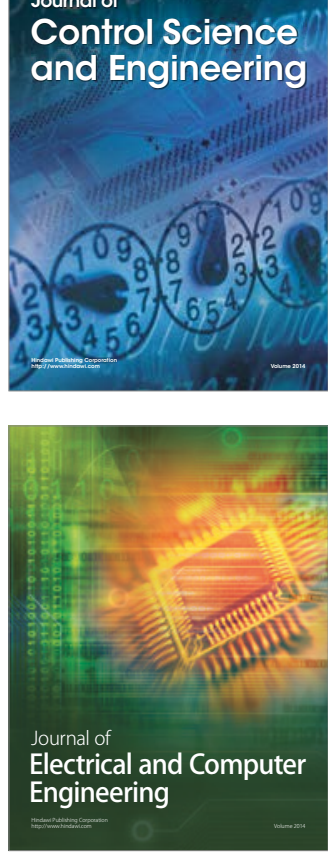

Distributed

Journal of

Control Science

and Engineering
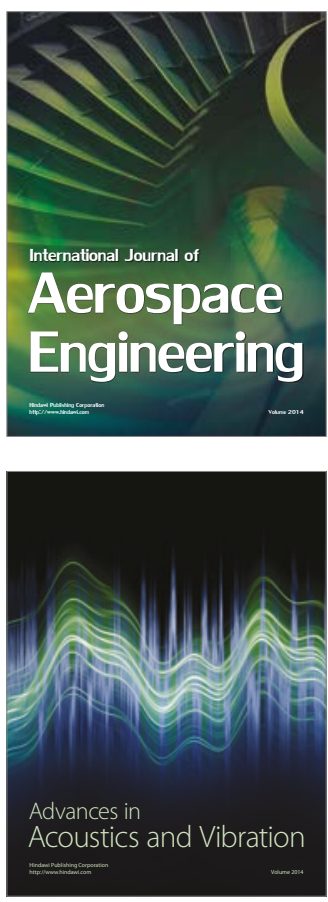

Sensor Networks 